\title{
Parametric Investigation of Repairing Cracked Pressure Vessel Using Composite Patch
}

\author{
Aghil Shavalipour* and Ramin Karimi \\ Department of Mechanical Engineering, Velayat University, Iranshahr, Iran
}

Received 21 December 2018; Accepted 14 September 2019

\begin{abstract}
In this study the reinforcement of a cracked pressure vessel was investigated using composite patch. The effect of the mechanical and geometrical properties of the patch on the Stress Intensity Factor (SIF) at crack tip was studied. The proposed model was initially validated and the behavior of the cracked vessel was then simulated for various crack dimensions. It was seen that the effect of crack length on the SIF is almost linear. The effect of fiber orientation angle in the single-layer and double-layer composite patch was studied. It was observed that the best results can be achieved when the orientation of fibers is perpendicular to that of crack. It was also obtained that growing the radius of the reservoir will increase the value of SIF at the crack tip.
\end{abstract}

Keywords: Composite patch; Pressure vessels; Stress intensity factor

\section{Introduction}

The role of pressure vessels in the industry is significantly important as these structures are able to store liquids and gases under high pressure. Special emphasis is placed upon the strength of the pressure vessels to prevent explosion as a result of rupture. In addition to manufacturing procedures, environmental effects like corrosion can play a critical role in the cracked vessels. The size of the crack may reach to a critical dimension and it may cause disastrous failure in the pressure vessels and pipelines during the operation $[1,2]$. Repairing steel vessels was traditionally carried out by replacing the cracked segment with a new loop or strengthening the damaged section using an external sleeve [3]. In recent years, there has been an increasing interest in using fiber-reinforced polymer (FRP) as an alternative repair system for pipelines. Using FRPs provide various benefits namely, superb corrosion protection, decent fatigue protection, and lower coefficient of thermal expansion. An additional advantage of FRP is the numerous ways in which polymers and fibers can be combined in a material to suit the specific needs of a structure [4]. Thus, investigating different parameters to reduce SIF and to seize crack growth plays a critical role in the maintenance of pressure vessels.

Recently, many studies have been carried out on the performance of composite overwrap repair system to understand the effects of different parameters $[5,6]$ and different loading conditions [6,7]. Chen and Pan [8] investigated the behavior of composite overwrapped pressure vessels under fracture using the axial crack in inner surface. Their results show that the value of SIF in the pressure vessels was significantly decreased by employing the composite patch. In 2009, Hocine et al. [9] carried out an experimental

*E-mail address: a.shavalipour@velayat.ac.ir

ISSN: 1791-2377 @ 2019 School of Science, IHU. All rights reserved.

doi:10.25103/iestr.124.17 and analytical investigation on the inspection of a graphite/epoxy hydrogen reservoir. Gozin and Aghaie [10] assessed quarter-elliptical crack growth utilizing 3D finite element technique and also crack closure method. In another study, Valentin and Arrat [11] used finite element approach to study the SIF of a semi-elliptical crack in the single and double-layered spherical shells. The effect of semi-elliptical cracks was also investigated by Atluri and Kathiresan [12], using finite element methods. A comprehensive review of FE modeling of pressure vessels and pipes was carried out by Mackerel [13] theoretically and experimentally. Shahani and Kheirikhah [14] analyzed SIF in the semi-elliptical cracks located on the surface of pressurized tubes. In the study which was introduced by Kim et al [15], longitudinal cracks in a cylindrical shell were inspected using the mechanics of nonlinear fracture. In another research study that was reported by Xie [16], SIF in a cracked pressure vessel was investigated analytically.

Alizadeh and Dehestani [17] concentrated on the analytical and numerical calculation of the critical internal load in a pressure vessel containing a longitudinal edge crack. The capacity of vessel was calculated based on the theoretical fracture method for seven material properties, different crack lengths, and vessel wall thickness. Benziane et al. [18] examined the repair of gas pipelines using carbon-epoxy composites. Assuming a longitudinal crack (applying Ifailure mode), the effect of number of composite layers was investigated. They applied FE method to calculate stress intensity at a crack tip.

Although many researches are carried out on damaged pipelines, just few studies are addressed to analyze SIF in the reinforced pressure vessels. This study is focused on the reinforcement of the damaged pressure vessels using composite patches. The effect of the length, thickness and fiber angles of the patch on the repair of a cracked pressure vessel was investigated in detail. It is shown that changing patch material and patch geometrical properties can attenuate 
the SIF in the crack tip of a pressure vessel significantly. All numerical simulations were carried out using ABAQUS software.

\section{Theoretical Analysis}

The investigation of the failure behavior of supposed pressure vessel was conducted based on fracture mechanic theories. Fracture mechanics focuses on the analyzing the structures containing initial cracks that can affect the load-carrying capacity of an engineering structures. In the theoretical section of current paper, it is assumed that there is an initial crack in the internal side of the thickness of the supposed pressure vessel. Characteristic quantity which defines the propensity of the crack to extend was determined. This quality depends on the failure criterion which is used in the modeling of problem. In this study, the stress intensity factor as a failure criterion was applied. Figure 1 indicates important parameters in analytical calculation of stress intensity factor. Geometrical properties of base model is shows in table 1. The failure criterion is expressed by Eq. (1).

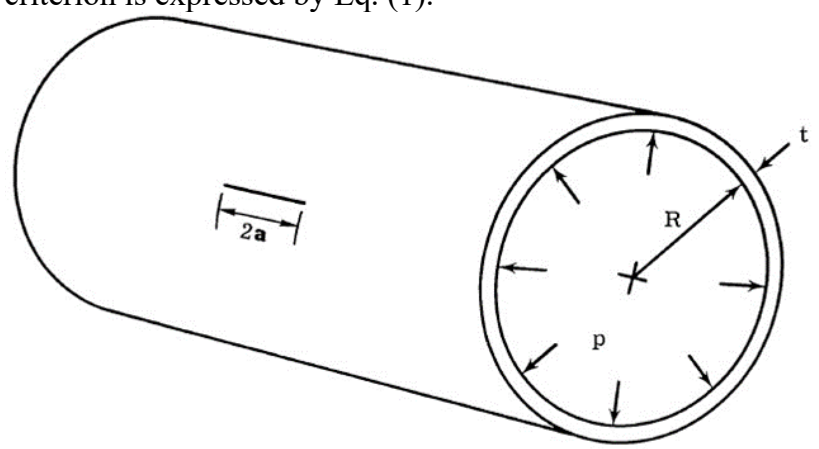

Fig. 1. Different parameter that influence analytical calculation

Table 1. Geometrical Properties of Base Model

\begin{tabular}{c|c|c|c|c|c|c}
\hline $\begin{array}{c}\text { Geometrical } \\
\text { properties }\end{array}$ & $\mathbf{R}(\mathbf{m m})$ & $\mathbf{t}(\mathbf{m m})$ & $\mathbf{2 a ( m m )}$ & $\mathbf{P}(\mathbf{M P a})$ & $\mathbf{E}(\mathbf{G P a})$ & $\boldsymbol{\varepsilon}$ \\
\hline Value & 147 & 17.5 & 50 & 30 & 207 & 0.3 \\
\hline
\end{tabular}

$\mathrm{K}_{\mathrm{I}}$ in Eq. (1) is stress intensity factor at the crack tip which depends on the applied load, the initial crack length and the geometrical configurations of the cracked plate

$$
k_{I}=\sigma \sqrt{\pi a} \times F
$$

The amount of $\sigma$ can be calculated from Eq. (2), where $\sigma$ is circumferential stress, $P$ is internal pressure of the vessel and $\mathrm{R}$ and $\mathrm{t}$ are the radius and the thickness of the vessel, respectively.

$\sigma=\frac{p \times r}{t}=\frac{30 \times 147}{17.5}=252$

$$
F=F_{t}=\left(1+0.52 \lambda_{t}+1.29 \lambda_{t}^{2}-0.074 \lambda_{t}^{3}\right)^{\frac{1}{2}}
$$

In this formula, $\lambda_{t}$ is the crack correction parameter along the wall and its value is between $0 \leq \lambda_{t} \leq 10$ and is obtained from $\lambda_{t}=a / \sqrt{R t}$. The above relation is used to consider the effect of tank buckling on the intensity of stress. In this case, it is assumed that the Poisson ratio is equal to $1 / 3$.

$$
\begin{gathered}
\lambda_{t}=\frac{a}{\sqrt{r t}}=\frac{0.025}{\sqrt{0.147 \times 0.0175}}=0.49 \Rightarrow F=1.247 \Rightarrow k_{I} \\
=88
\end{gathered}
$$

\section{Method Verification}

A pipeline with a longitudinal crack was considered. In order to ensure the accuracy of the numerical modeling, the model which was addressed by Benziane et al. [18] was initially built and results were then compared accordingly. The geometry of the model is shown in Figure 2. The length, radius and thickness of the pipe [18] were $1000 \mathrm{~mm}, 147 \mathrm{~mm}$ and 17.5 $\mathrm{mm}$, respectively.

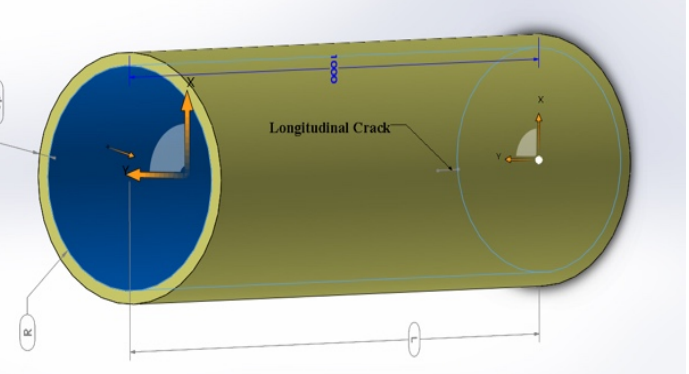

Fig. 2. Pipeline with longitudinal crack and Geometrical model

To compare the results of current study against those which are addressed in reference [18], a pipe with crack length $50 \mathrm{~mm}$ under internal pressure $30 \mathrm{MPa}$ was considered. The geometry of the 3D model was first built in ABAQUS software and a longitudinal crack was then designed in the middle of the pipe (Figure 3 ).

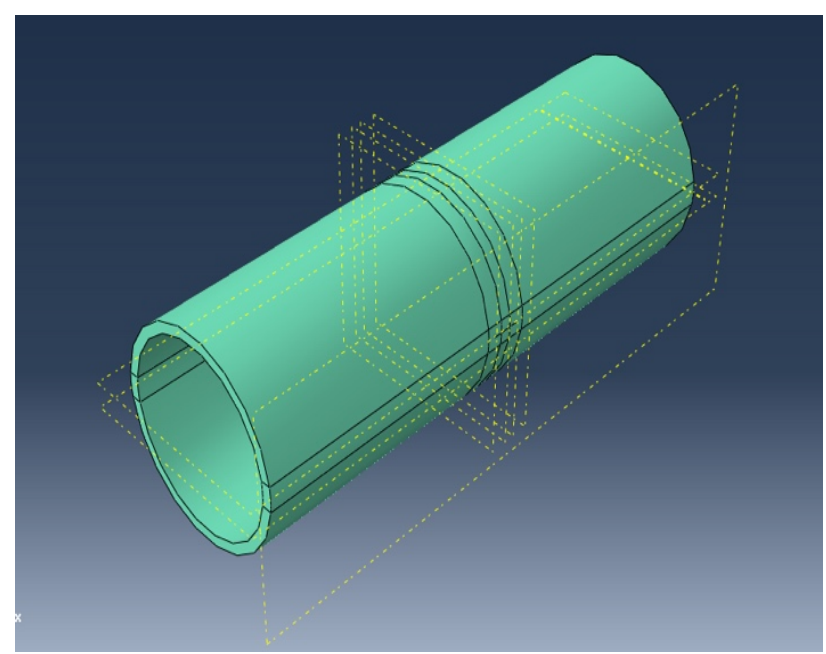

Fig. 3. Geometry of a cracked tank model

The modulus of elasticity and Poisson's ratio of the considered pipe were $207 \mathrm{GPa}$ and 0.3, respectively. The mechanical properties of carbon/epoxy composite patch are tabulated in Table 1.

Table 2. Mechanical properties of carbon/epoxy composite materials

\begin{tabular}{c|c|c|c|c|c|c|c|c|c}
\hline $\begin{array}{c}\text { Mechan } \\
\text { ical } \\
\text { propert } \\
\text { ies }\end{array}$ & $\begin{array}{c}\mathrm{E}_{11} \\
(\mathrm{GP}\end{array}$ & $\begin{array}{c}\mathrm{E}_{22} \\
(\mathrm{GP} \\
\text { a) }\end{array}$ & $\begin{array}{c}\mathrm{E}_{33} \\
(\mathrm{GP} \\
\mathrm{a})\end{array}$ & $\begin{array}{c}\mathrm{G}_{12} \\
(\mathrm{GP} \\
\mathrm{a})\end{array}$ & $\begin{array}{c}\mathrm{G}_{13} \\
(\mathrm{GP} \\
\text { a) }\end{array}$ & $\begin{array}{c}\mathrm{G}_{23} \\
(\mathrm{GP} \\
\text { a) }\end{array}$ & $\begin{array}{c}\varepsilon \\
12\end{array}$ & $\begin{array}{c}\varepsilon \\
13\end{array}$ & $\begin{array}{c}\varepsilon \\
23\end{array}$ \\
\hline Value & 135 & 10 & 10 & 5 & 5 & 5 & 0.3 & 0.3 & 0.3 \\
\hline
\end{tabular}




\section{Results and Discussions}

To validate the results, the SIF at the crack tip of a pressure tube was calculated using ABAQUS software. The obtained results were then compared with those which are available in the reference [18]. According to the results presented in reference [18], the value of the stress intensity factor in the first mode was approximately $80 \mathrm{MPa} \sqrt{\mathrm{m}}$. Based on the simulation, SIF in this study was found to be $82.7 \mathrm{MPa} \sqrt{ } \mathrm{m}$. It can be seen that the error of the obtained SIF value is below $3.4 \%$. A comparison of the results reveals the accuracy of current model. The rest of this paper is dedicated to investigate the SIF in the reservoir. Two ends of the pipe as it is depicted in Figure 4 were clamped using two plates and the pipe model was then converted to a reservoir.

To investigate the effect of composite patch on the mechanical behavior of reservoir, the following parameters were considered:

1- Effect of the crack length

2- Effect of the composite fiber angle

3- Effect of the crack length and fiber angles in twolayer composite patch

4- Effect of the reservoir radius

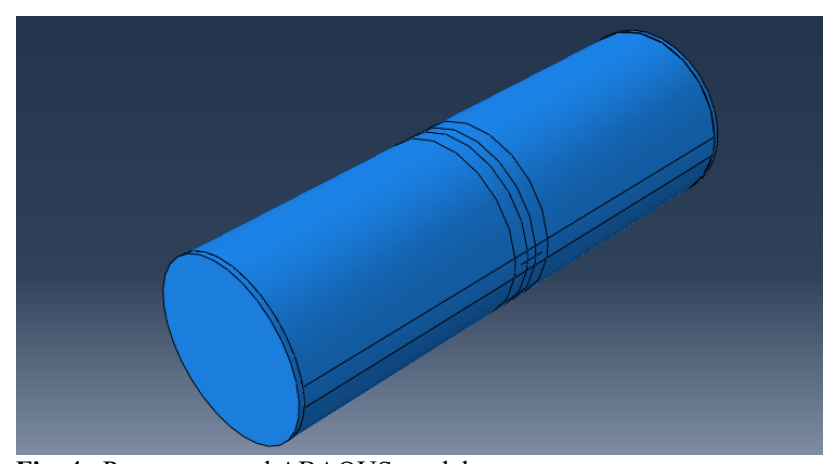

Fig. 4. Pressure vessel ABAQUS model

\subsection{Effect of the length of the crack}

The stress intensity factor in the reservoir with thickness 17.5 $\mathrm{mm}$ was studied for different crack lengths $(40,50,60,70$ and $80 \mathrm{~mm}$ ). Results corresponding to the crack length $80 \mathrm{~mm}$ were finally compared with the previous results. Figures 5 a) and b) show the Von-Misses stress for an 80-mm long crack. It can be observed that using composite patch has reduced Von-Misses stress significantly. The maximum stress at the crack tip has dropped from $35 \mathrm{MPa}$ to $18.5 \mathrm{MPa}$. The effect of the crack length $(40,50,60,70$ and $80 \mathrm{~mm})$ on the stress intensity factor is also shown in Figure 6. It can be seen that the relationship between these two parameters is almost linear and stress intensity factor increases by growing the crack length.

\subsection{Effect of Composite Fiber Angle}

All analyses in the previous parts were carried out considering the assumption that the fibers alignment in the corrective composite layer was perpendicular to the crack direction $\left(90^{\circ}\right)$. In order to understand the effect of fiber angles on stress intensity factor at the crack tip, four different angles $\left(0^{\circ}\right.$, $45^{\circ}, 30^{\circ}$ and $60^{\circ}$ ) of fibers were considered. Also, due to the change in the direction of the fiber, the stresses in the reservoir body were calculated. In Figures $7 \mathrm{a}-\mathrm{c}$, the effect of changing the angle of composite patch fibers on the VonMisses stresses is depicted. It is shown that no significant difference in the maximum stress is occurred. It should be noted that according to Figure 7 a to $\mathrm{c}$ Von-Misses stress at two ends of reservoir is much more than that of middle part. In the middle of the reservoir, which has the least stress, the angle of the fibers is effective in stress distribution. The influence of the fiber angle on the Von-Mises stress of the crack tip is shown in Figures 8 a to d. When the angle is $90^{\circ}$, the value of stress is $21 \mathrm{MPa}$. However, by decreasing the angle of fibers to $60^{\circ}, 45^{\circ}, 30^{\circ}$ and $0^{\circ}$, stress value increases accordingly. For angles of 60 to 0 degrees, the stress values were found to be $24.2,25.4,26$, and $26.3 \mathrm{MPa}$, respectively. The effect of the fiber direction on the stress intensity factor was also presented in Fig. 9. It can be realized that the stress intensity factor for a state where the fiber angle is $90^{\circ}$ is 1.92 $\mathrm{MPa} \sqrt{\mathrm{m}}$. By decreasing fiber angle, the stress intensity coefficient rises significantly. For angles $0^{\circ}$ and $45^{\circ}$ degrees, $\mathrm{SIF}$ was found to be 2.42 and $2.33 \mathrm{MPa} \sqrt{\mathrm{m}}$, respectively.

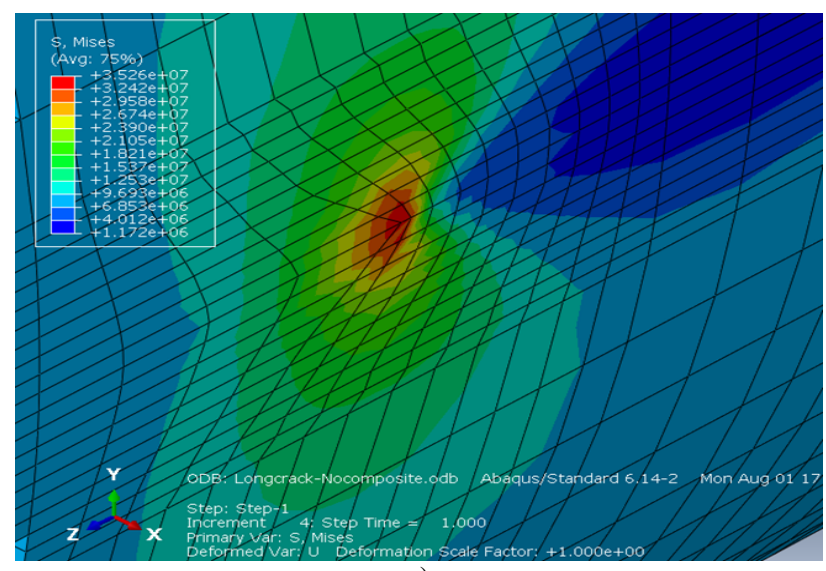

a)

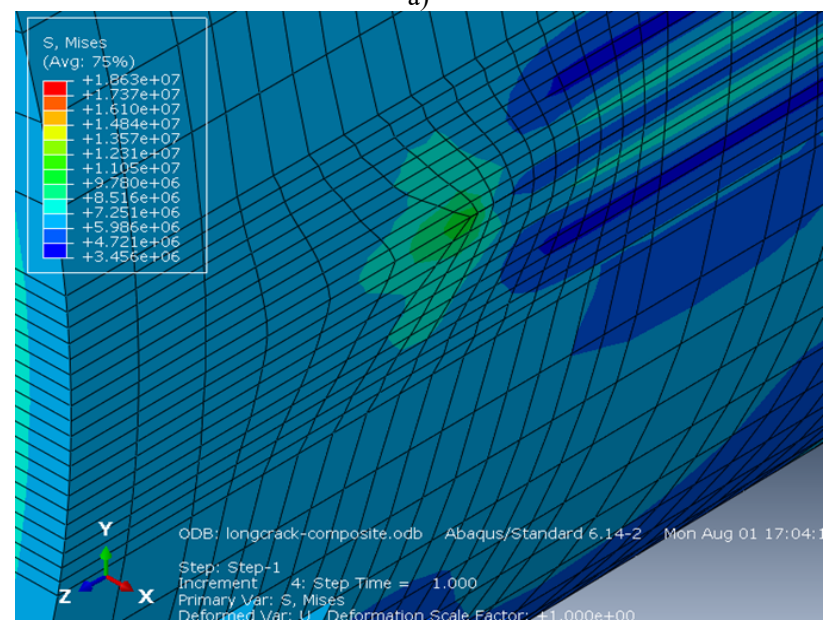

b)

Fig. 5.a) Von-Misses stress around $80 \mathrm{~mm}$ long crack (without composite patch) and b)Von-Misses stress around $80 \mathrm{~mm}$ long cracks (with composite patch)

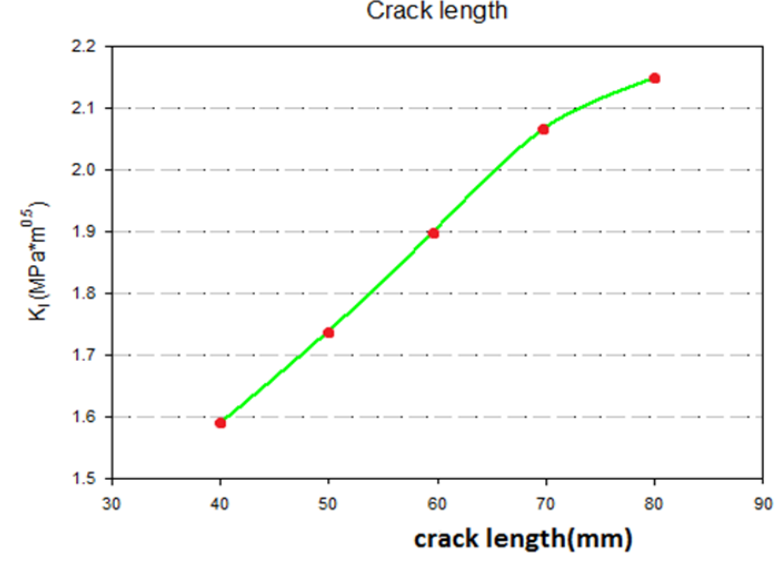

Fig. 6. Effect of crack length on the stress intensity factor 


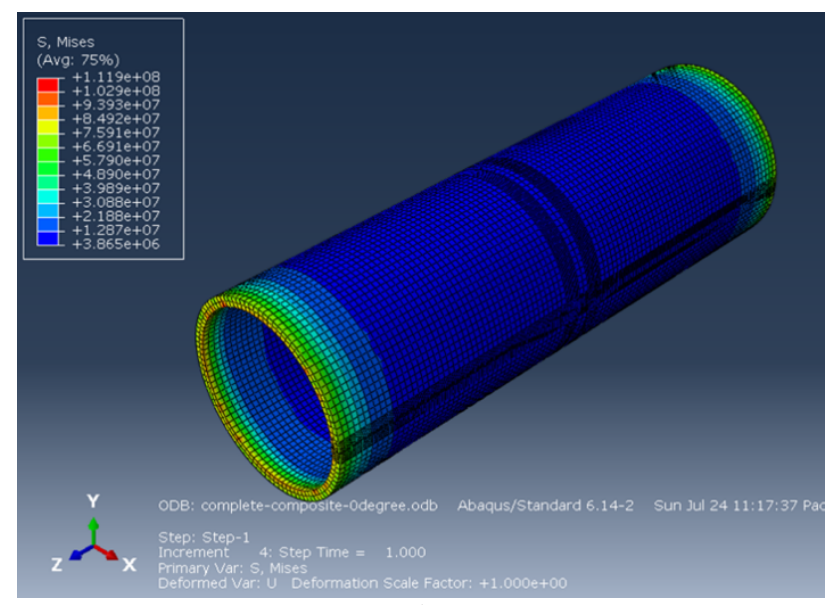

a)

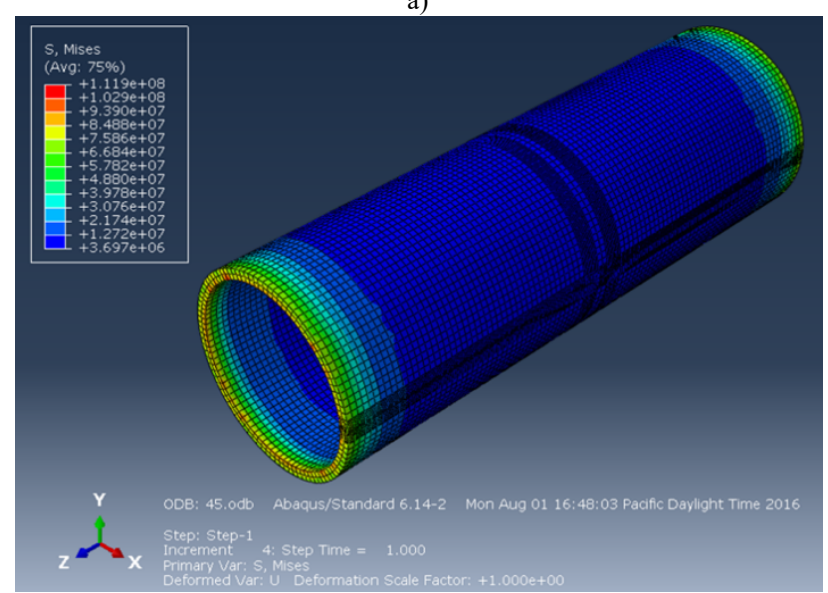

b)

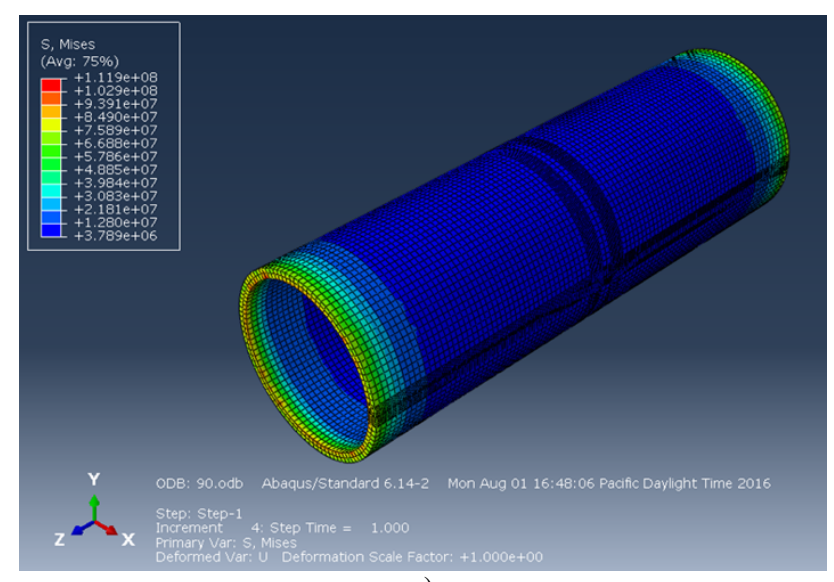

c)

Fig. 7. a) Von-Mises stress for $90^{\circ}$ fiber alignment. b) Von-Mises stress for $45^{\circ}$ fiber alignment and c)Von-Mises stress for $0^{\circ}$ fiber alignment.

\subsection{Effect of the fiber angles in two layers and different crack lengths}

Figure 10 shows the effect of the fiber angles in a two-layer composite patch with various crack lengths. Various fiber directions $\left(\left[0^{\circ} / 0^{\circ}\right],\left[90^{\circ} / 90^{\circ}\right],\left[45^{\circ} / 45^{\circ}\right],\left[60^{\circ} / 60^{\circ}\right],\left[0^{\circ} / 90^{\circ}\right]\right.$, and $\left.\left[0^{\circ} / 45^{\circ}\right]\right)$ were considered and studied. According to Figure 10 it can be seen that the highest and lowest SIF at the crack tip occur when fibers angle of layers is $0^{\circ}$ and $90^{\circ}$, respectively. In Figure 10, the maximum SIF after $\left[0^{\circ} / 0^{\circ}\right]$ is related to angles $\left[0^{\circ} / 45^{\circ}\right]$ and subsequently $\left[45^{\circ} / 45^{\circ}\right]$. It can be observed that after fibers angle $\left[90^{\circ} / 90^{\circ}\right]$ the minimum SIF goes for $\left[60^{\circ} / 60^{\circ}\right]$ and $\left[0^{\circ} / 90^{\circ}\right]$. Von-Misses stress values at the cracks tip are shown in the Figure 10a-10d. These results are shown for a case where the cracks length are $50 \mathrm{~mm}$. In Figure 11, all subfigures are represented by three numbers, the first number is the crack length $(50 \mathrm{~mm})$, the second and third numbers represent the angle of the fibers in two different layers. Since the stress value is proportional to the stress intensity factor, the stress-related results follow exactly the same order as it was observed in Figure 10. It means that the highest stress $(20.2 \mathrm{MPa})$ occurs in the fibers angle $\left[0^{\circ} / 0^{\circ}\right]$ and obviously the least stress $(15.3 \mathrm{MPa})$ happens in angle $\left[90^{\circ} / 90^{\circ}\right]$.

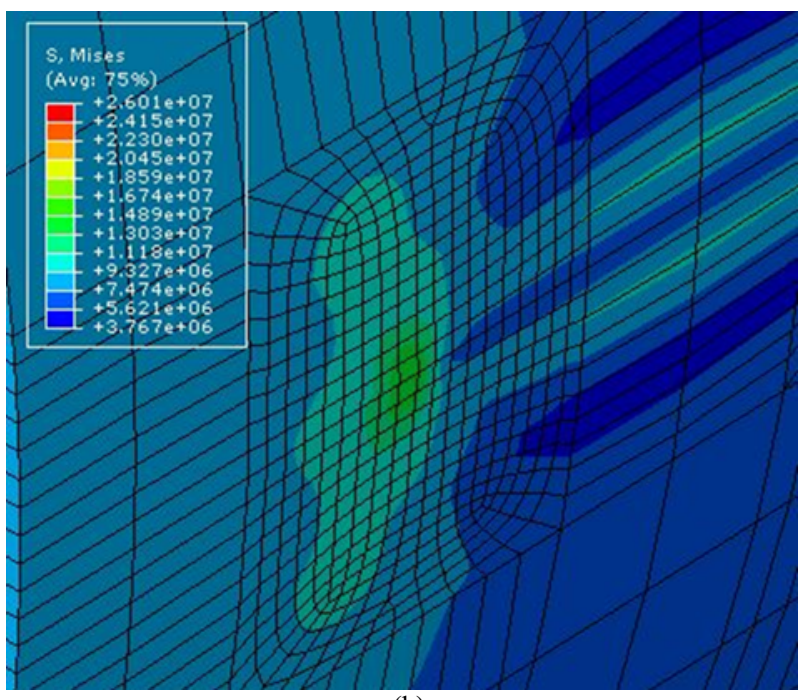

(b) 


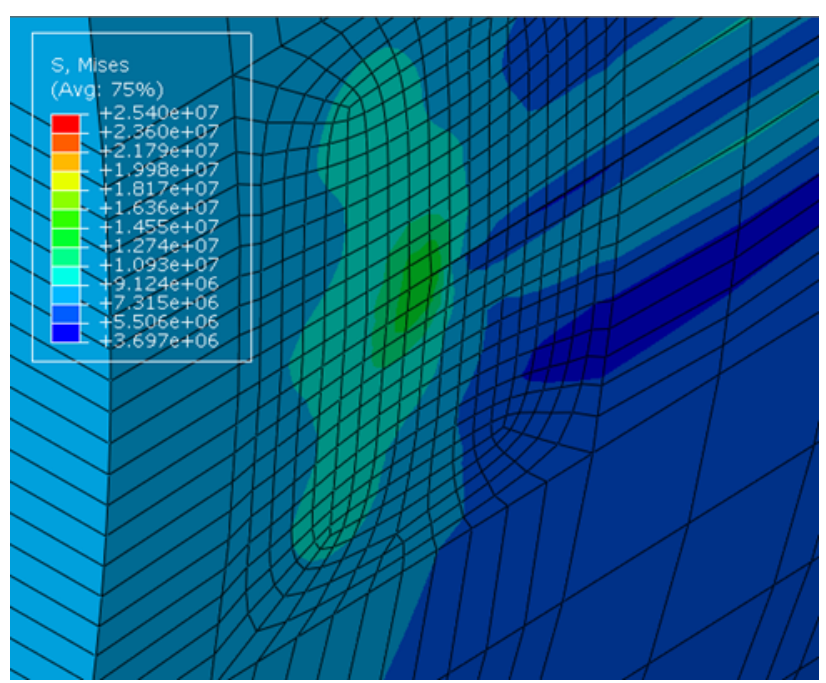

(c)

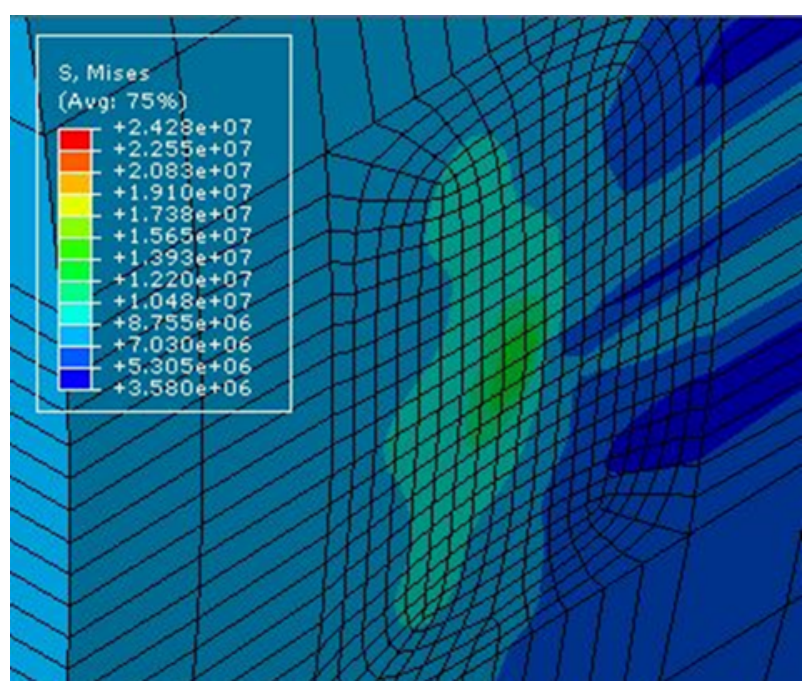

(d)

Fig. 8. Von-Mises stress for a- $0^{\circ}, \mathrm{b}-30^{\circ}, \mathrm{c}-45^{\circ}, \mathrm{d}-60^{\circ}$ fiber alignment.

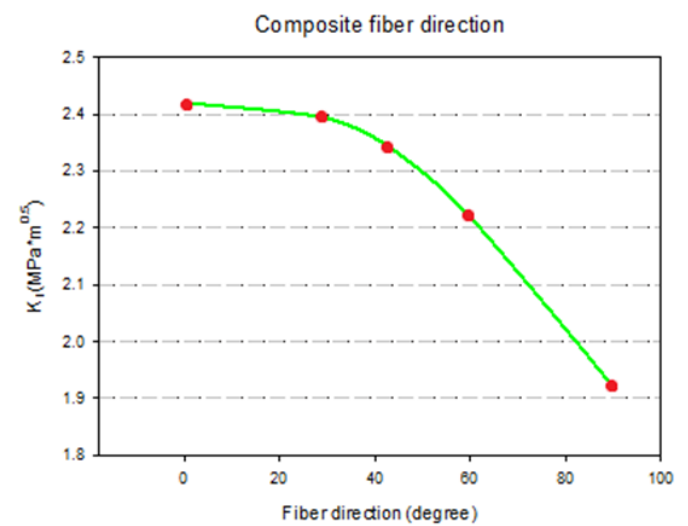

Fig. 9. Effect of fiber composite patch angle on stress intensity factor

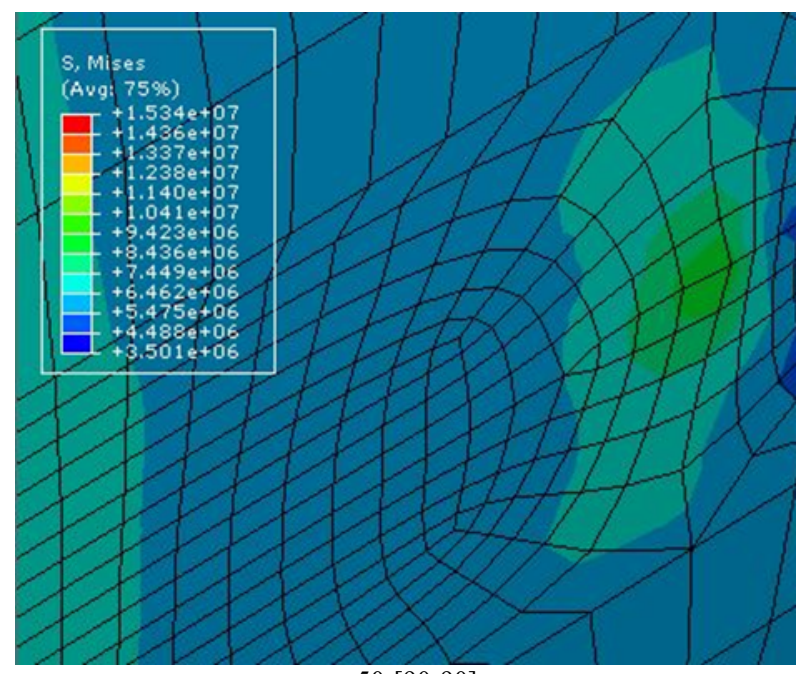

a-50-[90-90]

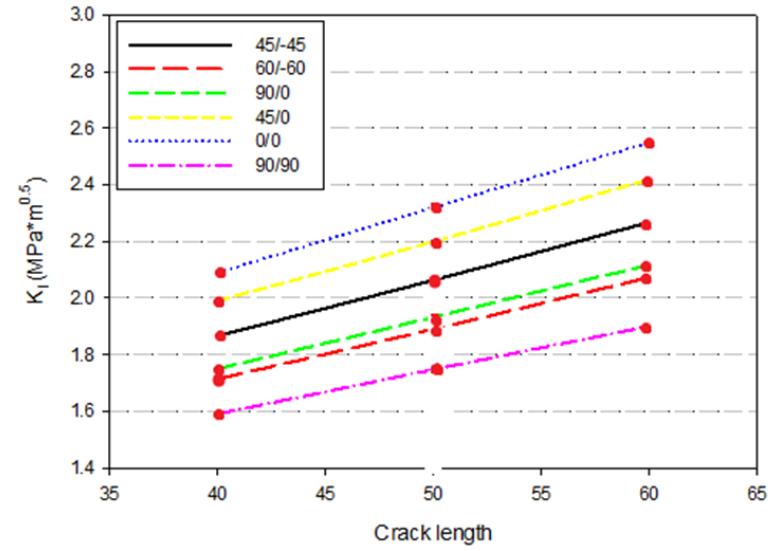

Fig. 10. The effect of fiber direction in double-layered fibers for different crack lengths

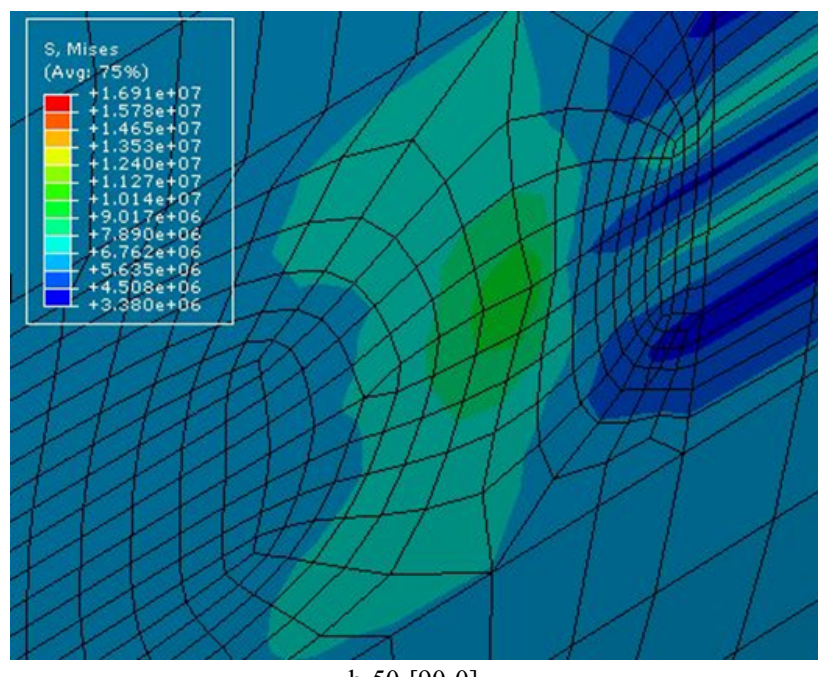

b-50-[90-0] 

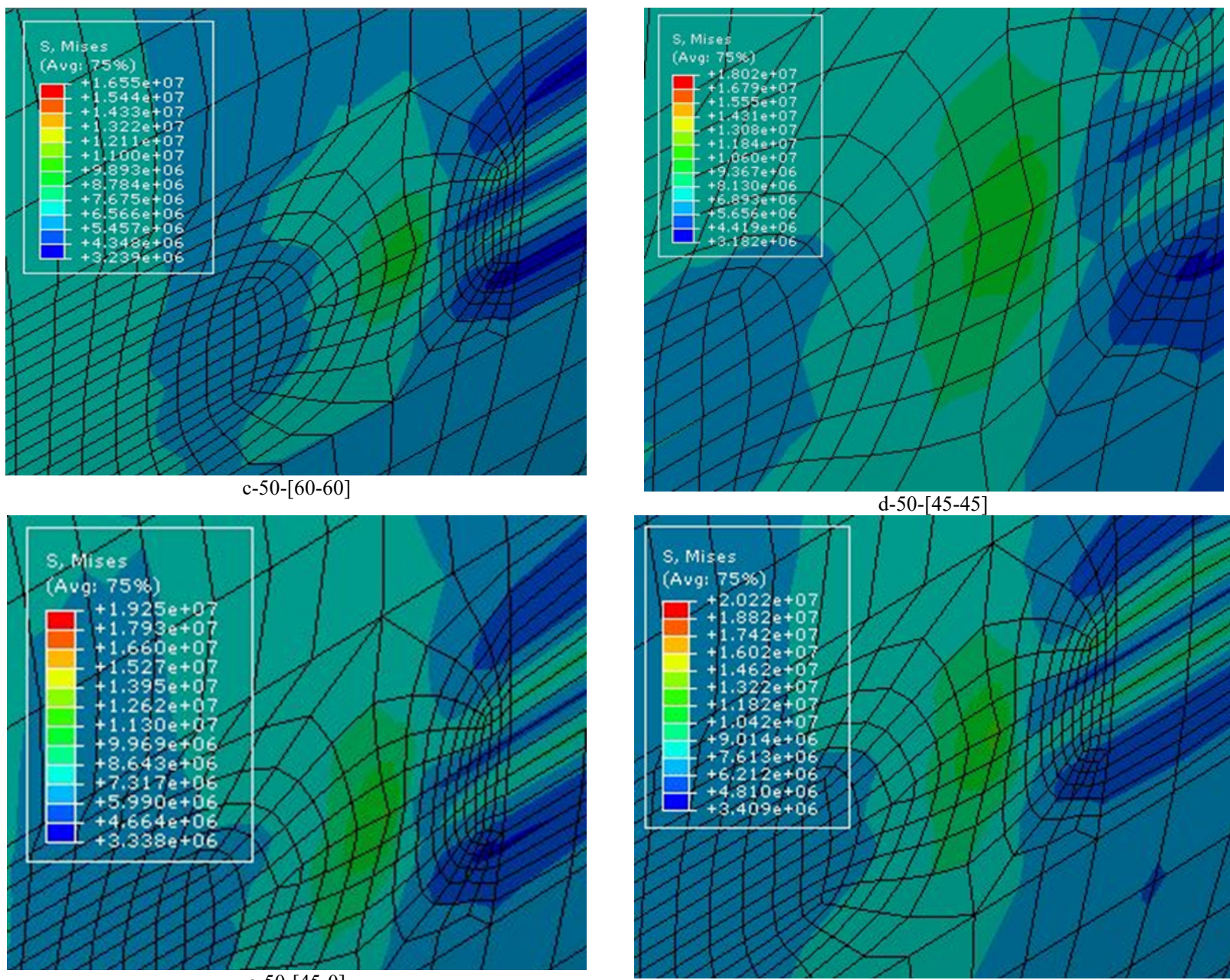

e-50-[45-0]

f-50-[0-0]

Fig. 11. values of Von-Mises stress for different layout of fibers in two layers

\subsection{Investigating the effect of reservoir radius}

Radius of reservoir is another parameter which affects significantly on the SIF values. The initial radius of the reservoir in this study was considered to be $150 \mathrm{~mm}$. To study the effect of reservoir radius, results for two other radii were calculated and compared. A reservoir with radius $200 \mathrm{~mm}$ is shown in Figure 12. The effect of reservoir radius on the VonMises stress is shown in Figures 13(a-d). It can be seen that by growing the radius, the value of stress increases. It is due to that fact that, since the pressure inside the reservoirs is constant, through increasing the inner surface of the reservoir the internal force growths accordingly. The maximum stress at the crack tip for a reservoir with radius $100 \mathrm{~mm}$ were calculated and it was concluded that using composite patch can reduce the maximum stress from $21.86 \mathrm{MPa}$ to $14.2 \mathrm{MPa}$. Similar results were observed for the reservoir with radius 200 mm; maximum stress dropped form 41.5 $\mathrm{MPa}$ (without patch) to $26.3 \mathrm{MPa}$ (with patch). As stated before, SIF values follow the same order as it was recorded for maximum stress at the crack tip. SIF values for different radii of the reservoir are tabulated in Table 2. Using composite patch, the SIF at the crack tip of reservoirs with radii $100 \mathrm{~mm}, 150 \mathrm{~mm}$ and 200 mm dropped from 1.93, 2.77 and $3.52 \mathrm{MPa} \sqrt{ } \mathrm{m}$ to $1.28,1.92$ and $2.44 \mathrm{MPa} \sqrt{\mathrm{m}}$, respectively.

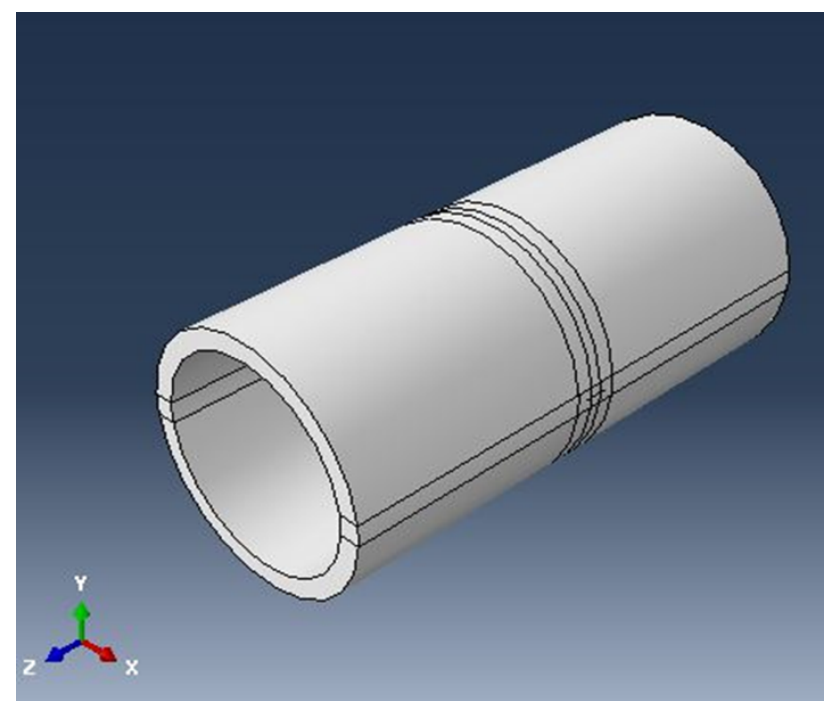

Fig. 12. A model made to investigate the effect of the radius of the reservoir $(\mathrm{r}=200 \mathrm{~mm})$ 


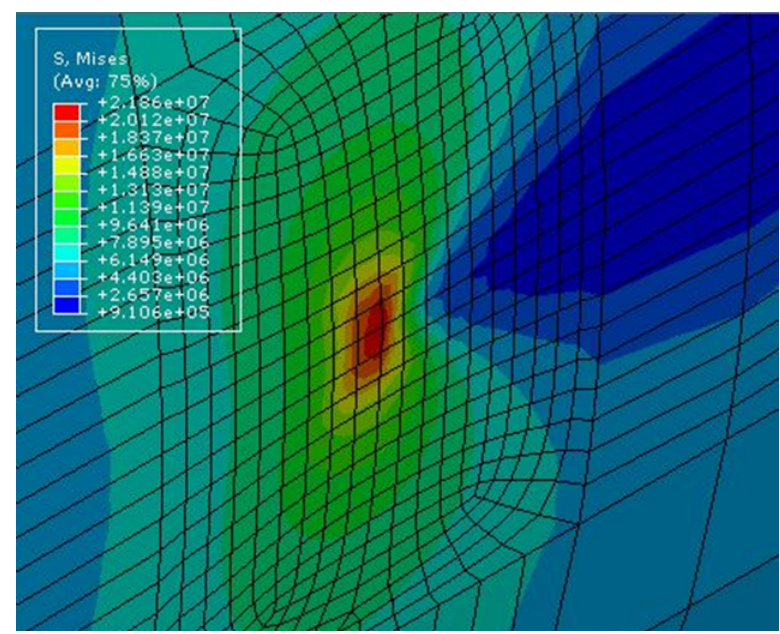

(a)

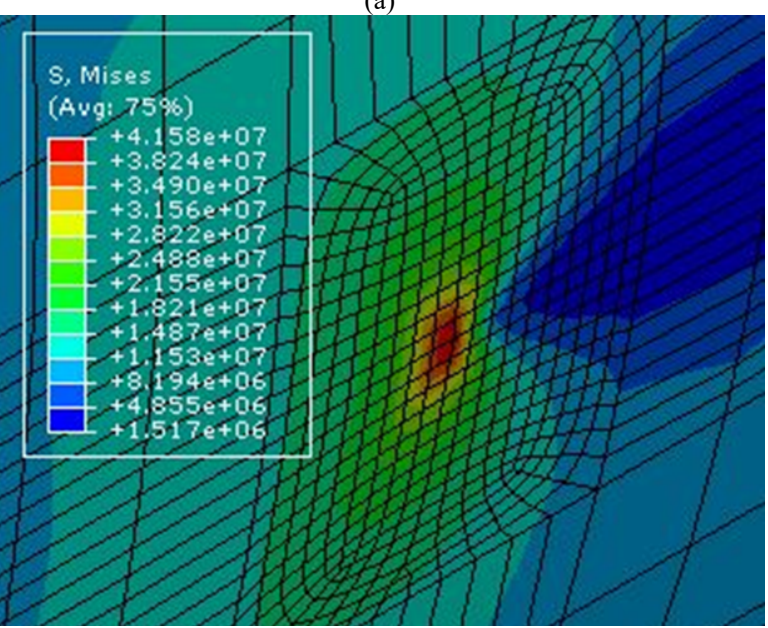

(c)

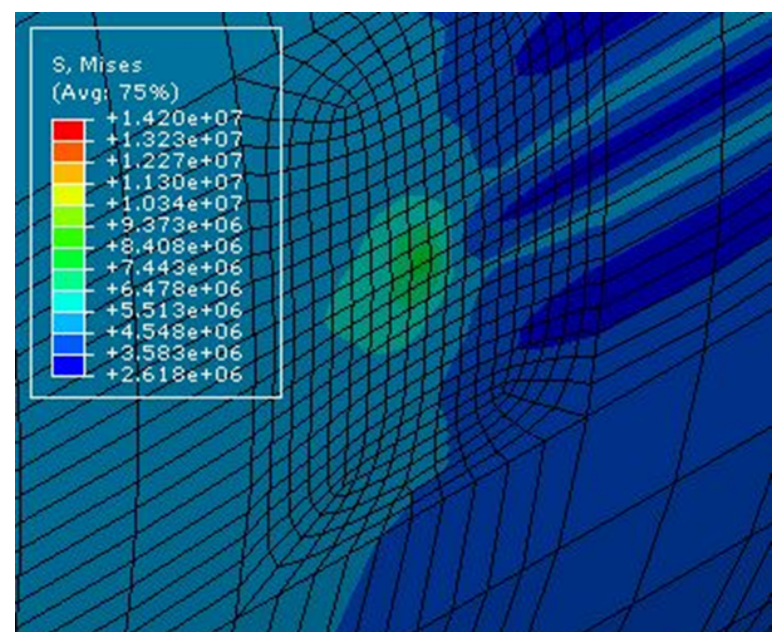

(b)

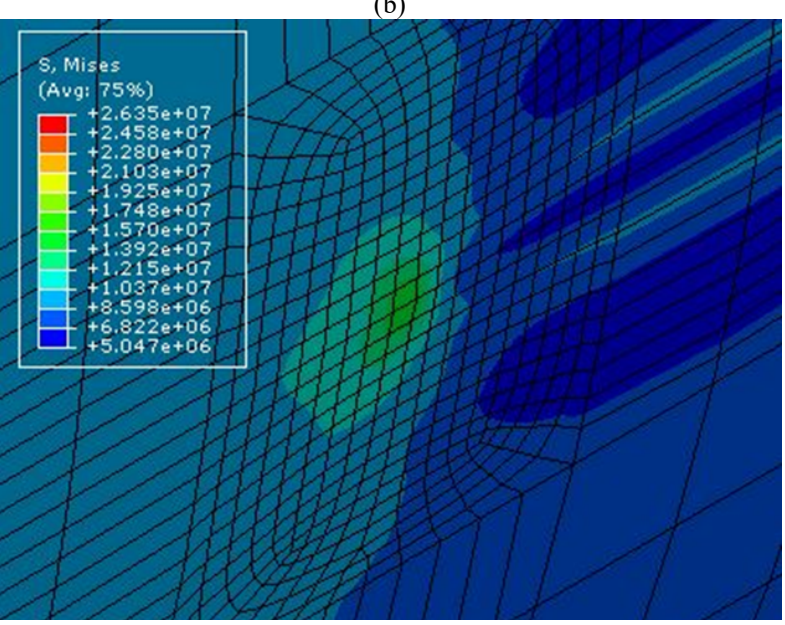

(d)

Fig. 13. Von-Mises stress around the tip of crack for a reservoir with (a) radius of $100 \mathrm{~mm}$ (without a composite patch) (b) radius of $100 \mathrm{~mm}$ (with a composite patch) (c) radius of $200 \mathrm{~mm}$ (without a composite patch) (d) radius of $200 \mathrm{~mm}$ (with a composite patch)

Table 3. Effect of reservoir radius on SIF

\begin{tabular}{c|c|c|c}
\hline $\begin{array}{c}\text { Radius } \\
(\mathbf{m m})\end{array}$ & $\begin{array}{c}\text { K1 } \mathbf{( M P a} \sqrt{ } \mathbf{m}) \\
\text { (without } \\
\text { composite } \\
\text { patch) }\end{array}$ & $\begin{array}{c}\text { K1 } \\
\mathbf{( M P a} \sqrt{ } \mathbf{m}) \\
\text { (with } \\
\text { composite } \\
\text { patch) }\end{array}$ & $\begin{array}{c}\text { Reduction } \\
\mathbf{( \% )}\end{array}$ \\
\hline 100 & 1.93 & 1.284 & 33.48 \\
150 & 2.77 & 1.92 & 30.68 \\
200 & 3.52 & 2.44 & 30.60 \\
\hline
\end{tabular}

\section{Conclusion}

In this study a cracked reservoir was retrieved using composite patch. The propagation of a crack in a structure highly depends upon the magnitude of stress. Stress intensity factor at the tip of crack is one of the crucial parameters that refers to crack propagation. Reinforcement of the reservoir using composite patch seizes the crack growth and aggrandizes the mechanical properties of the whole structure. Present study was prepared to investigate the effect of various geometrical and material properties of the composite patch on the SIF at a crack tip of a pressure vessel. Finite Element modeling of the pressure vessel was implemented and following conclusions were obtained:
1- Results indicate that the effect of crack length on the stress intensity factor is almost linear and by increasing the crack length the stress intensity factor growths accordingly.

2- The effect of fibers direction on a single-layer composite shows that maximum reinforcement fulfills when the angle of fibers in composite material are perpendicular to the crack direction. Obviously minimum protection occurs when the direction of fibers is parallel to that of crack.

3- Using two-layer composite patch with various fiber directions demonstrates that maximum buttress applies when the fibers direction in two-layer composite are mutually $90^{\circ}$. The forming of the fibers direction parallel to that of crack produces the lowest reinforcement.

4- Based on the results, increase in the radius of the reservoir will raise the load at the crack tip, which ultimately leads to an increase in the stress intensity factor.

This is an Open Access article distributed under the terms of the Creative Commons Attribution License

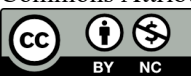




\section{References}

[1] E. Olsø, B. Nyhus, E. Østby, E. Berg, K. Holthe, B. Skallerud, et al., "Effect of embedded defects in pipelines subjected to plastic strains during operation," in The Eighteenth International Offshore and Polar Engineering Conference, 2008.

[2] X. Qian, "KI-T estimation for embedded flaws in pipes-Part II: Circumferentially oriented cracks," International Journal of Pressure Vessels and Piping, vol. 87, pp. 150-164, 2010.

[3] M. Mohitpour, "Pipeline Design \& Construction. 2nd eds," New York, NY, 2003.

[4] U. Meier, "Carbon fiber-reinforced polymers: modern materials in bridge engineering," Structural Engineering International, vol. 2, pp. 7-12, 1992.

[5] C. Alexander, L. Cercone, and J. Lockwood, "Development of a Carbon-Fiber Composite Repair System for Offshore Risers," in ASME 2008 27th International Conference on Offshore Mechanics and Arctic Engineering, 2008, pp. 389-405.

[6] C. Alexander and O. O. Ochoa, "Extending onshore pipeline repair to offshore steel risers with carbon-fiber reinforced composites," Composite Structures, vol. 92, pp. 499-507, 2010.

[7] A. Shouman and F. Taheri, "Compressive strain limits of composite repaired pipelines under combined loading states," Composite Structures, vol. 93, pp. 1538-1548, 2011.

[8] J. Chen and H. Pan, "Stress intensity factor of semi-elliptical surface crack in a cylinder with hoop wrapped composite layer," International Journal of Pressure Vessels and Piping, vol. 110, pp. $77-81,2013$.

[9] A. Hocine, D. Chapelle, M. Boubakar, A. Benamar, and A. Bezazi, "Experimental and analytical investigation of the cylindrical part of a metallic vessel reinforced by filament winding while submitted to internal pressure," International journal of pressure vessels and piping, vol. 86, pp. 649-655, 2009.

[10] M.-H. Gozin and M. Aghaie-Khafri, "Quarter elliptical crack growth using three dimensional finite element method and crack closure technique," Journal of Mechanical Science and Technology, vol. 28, pp. 2141-2151, 2014

[11] G. Valentin and D. Arrat, "Stress intensity factors of semi-elliptical cracks in single-or double-layered spherical shells," International journal of pressure vessels and piping, vol. 48, pp. 9-20, 1991.

[12] S. N. Atluri and K. Kathiresan, "3D analyses of surface flaws in thick-walled reactor pressure-vessels using displacement-hybrid finite element method," Nuclear Engineering and Design, vol. 51, pp. 163-176, 1979

[13] J. Mackerle, "Finite elements in the analysis of pressure vessels and piping, an addendum: A bibliography (2001-2004)," International Journal of Pressure Vessels and Piping, vol. 82, pp. 571-592, 2005.

[14] A. Shahani and M. Kheirikhah, "Stress intensity factor calculation of steel-lined hoop-wrapped cylinders with internal semi-elliptical circumferential crack," Engineering fracture mechanics, vol. 74, pp. 2004-2013, 2007.

[15] Y.-J. Kim, J.-S. Kim, Y.-J. Park, and Y.-J. Kim, "Elastic-plastic fracture mechanics method for finite internal axial surface cracks in cylinders," Engineering Fracture Mechanics, vol. 71, pp. 925-944, 2004.

[16] Y. Xie, "An analytical method on circumferential periodic cracked pipes and shells," International journal of solids and structures, vol. 37, pp. 5189-5201, 2000.

[17] E. Alizadeh and M. Dehestani, "Analytical and numerical fracture analysis of pressure vessel containing wall crack and reinforcement with CFRP laminates," Thin-Walled Structures, vol. 127, pp. 210$220,2018$.

[18] M. Meriem-Benziane, S. A. Abdul-Wahab, H. Zahloul, B. Babaziane, M. Hadj-Meliani, and G. Pluvinage, "Finite element analysis of the integrity of an API X65 pipeline with a longitudinal crack repaired with single-and double-bonded composites," Composites Part B: Engineering, vol. 77, pp. 431-439, 2015. 